\title{
Waste management alternatives: (Dis)economies of scale in recovery and decoupling
}

\author{
Julia Swart*, Loek Groot \\ Utrecht University, Utrecht School of Economics, Netherlands
}

\section{A R T I C L E I N F O}

\section{Article history:}

Received 1 November 2013

Received in revised form

11 September 2014

Accepted 12 November 2014

Available online 4 December 2014

\section{JEL classification:}

Q01

Q53

Q56

Keywords:

Waste disposal

Recycling

Landfill

Decoupling

Environmental Kuznets Curve

Economies of scale

\begin{abstract}
A B S T R A C T
This paper formulates a theoretical model which allows different waste management strategies in equilibrium, depending on the technology of waste recovery and the utility functional specification. In the model there are two waste treatment alternatives: 'not-recovered waste', composed of landfill and incineration without recovery and 'recovered waste', which is the aggregate of recycling, composting and incineration with recovery. We show that if recovery activities present constant or economies of scale then it is optimal to have zero not-recovered waste. The presence of diseconomies of scale in recovery of waste can either result in an equilibrium with zero or positive not-recovered waste, but recovery of waste is necessarily positive. We test for the presence of an EKC, and find that it is only compatible in our model when we assume decreasing marginal utility of consumption, and diseconomies of scale are limited. However, in the presence of (constant) economies of scale in recovery, we observe complete decoupling.
\end{abstract}

(c) 2014 Elsevier B.V. All rights reserved.

\section{Introduction}

Worldwide, recycling rates are increasing. On average, recycling rates for OECD countries more than doubled in between 1995 and 2008 , from $9.9 \%$ to $23.5 \%$ However, there are significant crosscountry differences. ${ }^{1}$ In 2008, Mexico's recycling rate, for example, was less than $4 \%$ of total waste treated, whereas South Korea reached the remarkable score of nearly $60 \%{ }^{2}$ Similarly, while landfill is the predominant waste management option in most developing nations, some developed countries have been able to completely eliminate this option from their waste management alternatives. The waste management strategy is not, however, only determined by a country's development level. Countries such as

\footnotetext{
* Corresponding author. Tel.: +310302539413.

E-mail address: j.swart@uu.nl (J. Swart).

1 In 2010, at one extreme we have for instance Bulgaria and Romania where the percentage of total waste treatment deposited onto or into land was $100 \%$ and 98.6\% respectively and at the other extreme Austria, Germany, the Netherlands and Switzerland, where it was less than $1 \%$ (EUROSTAT, 2012b).

2 Based on OECD online statistics on waste. We compute recycling rates as the share of recycled waste in total waste.
}

Luxembourg and Portugal have similar landfill rates (close to 50\%) while Luxembourg has more than 4 times the GDP per capita than Portugal. ${ }^{3}$ In this paper we formulate a theoretical model which allows different waste management strategies in equilibrium, depending on the technology of waste recovery and the utility functional specification. In our model there are two waste treatment alternatives: 'not-recovered waste', composed of landfill and incineration without recovery and 'recovered waste', which is the aggregate of recycling, composting and incineration with recovery. Our main purpose is to provide the microeconomic foundations of different waste treatment strategies based on assumptions which are more representative of the waste management state. For this purpose, we differentiate from the more general seminal paper by Andreoni and Levinson (2001), by allowing (i) non-recovered waste to be costly; (ii) (dis)economies of scale in recovered waste, and (iii) a non-linear utility function.

In the literature on waste, a recurrent theme is that of the Environmental Kuznets Curve (hereafter abbreviated as EKC). The

\footnotetext{
${ }^{3}$ Based on 2010 data. Data for landfilling rate is EUROSTAT (2012b), where landfilling rates considers total waste treated. The data for GDP per capita (constant US\$) comes from the World Bank, WDI.
} 
inverted U-shape of the EKC is a well-known hypothesized and empirically corroborated relationship between income and various indicators of environmental quality. ${ }^{4}$ Related to the EKC, the IPAT model states that environmental impact $(\mathrm{I})$ is the product of three elements: Population (P), per capita Affluence (A) and Technology (T) $\left(\mathrm{I}=\mathrm{P}^{*} \mathrm{~A}^{*} \mathrm{~T}\right)$. Mazzanti et al. (2007), e.g., describe the relationship between the EKC approach and the accounting identity proposed by the IPAT model. The component $\mathrm{T}$ can be associated to the decoupling hypothesis. In our paper, a technological parameter $\beta$ is similarly crucial to understanding the possibility of relative and absolute decoupling.

The literature analyzing the relationship between income and indicators of environmental quality considered different measures for the environmental good (or bad), such as carbon dioxide emissions and other greenhouse gases, waste generation, water pollutants, among others. Essentially, there are two strong mechanisms at work to produce such an outcome. When we become richer, the marginal value of increased consumption declines and the marginal disutility of pollution increases (if only in relative terms), so there comes a point at which the sacrifice (welfare loss) of reduced consumption because of abatement costs of recovery is less than the marginal disutility of more waste. A nonlinear relationship between a dirty and a clean good is no surprise when the marginal utility of consumption of the clean good is decreasing, and the marginal (dis)utility of consumption of the dirty good is constant (a standard representation in the literature). However, due to the practically unlimited possibility of landfill disposal and therefore a low and constant marginal disutility of waste, the point at which this mechanism starts to work can be at very high, maybe yet unobserved levels of GDP per capita. Therefore, reliance on this mechanism is risky, especially when pollutants are involved in which environmental damages are irreversible. According to the second mechanism more (gross) waste is produced when we become richer, which opens up the possibility to benefit from economies of scale in waste recovery. Both mechanisms are incorporated in our model, the first by means of assuming a declining marginal utility of consumption and constant disutility of waste, the second by means of the possibility of increasing returns to scale in recovery.

Our approach is similar to that of Andreoni and Levinson (2001) (hereafter $\mathrm{AL}$ ) in providing a micro-economic model of the linkages between consumption and different forms of waste treatment. AL (ibid.: 271) show that “... an EKC can be derived directly from the technological link between consumption of a desired good and abatement of its undesirable good". Their Theorem 1 states that for some sufficiently large income and under the conditions that pollution clean-up is a normal good and abatement technology exhibits increasing returns to scale, optimal pollution will ultimately become zero, that is the downward sloping part of the EKC will cut the horizontal axis at some point. More specifically, due to their Cobb-Douglas specification of abatement, the optimal consumption and abatement efforts are constant shares of resources per capita. When abatement technology is characterized by economies of scale, it follows that there is a range where pollution decreases as resources increase. The policy significance of the downward sloping part of the EKC is that, provided the turning point is not located at a too high level of per capita resources, continued economic growth and a clean(er) environment are compatible in the end. AL show that an inverse-U curve between pollution and income does not depend on changes in preferences as income rises, but solely on increasing returns of abatement. Their model as ours

\footnotetext{
4 There is no consensus, however, about the extent to which the EKC is ubiquitous. Stern (2004) provides a survey on the EKC showing that in many cases it is based on outcomes of statistical analyses which are not robust.
}

focusses attention on pollution as a by-product of consumption. However, in our model, set-up based on 'not-recovered waste' as the pollution variable, both pollution (such as landfill disposal) and abatement (such as recycling) are costly. This is a crucial difference to the model set-up by AL, in which not-recovered waste is assumed to be costless. Moreover, in our model the costs of recovery only depends on the amount of waste to be recovered and a technology parameter representing in- or decreasing returns to scale in recovery, whereas AL assume that recovery costs not only vary by the amount of waste to be recovered, but also by the level of consumption (see also footnote 8 below). It will turn out that these differences in assumptions have implications for the occurrence of (absolute or relative) decoupling between income and waste.

Using our more general specification model, we show that under constant or increasing returns to scale in recovery, there will always be complete decoupling, resulting in a state of full recovery and zero waste. Only under decreasing returns to scale, combined with a declining marginal utility of consumption, may an EKC with absolute and relative decoupling be observed. The latter is also illustrated empirically for a set of EU countries. These main results contrast with the ones found by AL, who show that an EKC result from increasing returns of abatement, regardless of preferences.

Recently, some papers attempted to investigate empirically the relationship between income and waste using cross-country data. Johnstone and Labonne (2004) use a database of municipal solid waste generation in OECD countries, for the period 1980-2000. They find that household municipal waste is less than unit elastic with respect to household final consumption expenditures. ${ }^{5}$ Thus, even though on average waste increases with income in OECD countries, the effect is less than proportional (relative decoupling). Mazzanti and Zoboli $(2008,2009)$ test for a Waste Kuznets Curve (WKC) using a sample of (25) member countries of the European Union for the period 1995-2005. The authors analyze the effect of income on municipal solid waste generation, incineration, recycling and landfill and do not find evidence for an overall WKC. As Johnstone and Labonne (2004), Mazzanti and Zoboli (2008, 2009) also find evidence of relative decoupling (specifically, a positive coefficient for the effect of consumption on waste, but a less than unity elasticity). Recycling, on the other hand, is positively related to income, with an elasticity higher than one. ${ }^{6}$ When looking at landfill waste alone, Mazzanti and Zoboli (2008, 2009) find evidence of a WKC and absolute decoupling. Finally, with respect to incineration their findings indicate a positive relationship with income. Mazzanti et al. (2012) take an economic-geographical perspective based on panel data on Italian data and find that absolute decoupling is present for landfilled waste, although not for waste generation. A recent paper by Kinnaman et al. (2014) analyze the socially optimal recycling rate, based on Japanese data, and found that given the social cost of waste management, the desirable recycling rate can be lower than the ones observed in developed countries.

In Section 2 we build a model in which pollution in the form of not-recovered waste can entirely be eliminated. Alternatively, waste recovery (as an abatement technology) could remove dirty activities completely. In this case, a quadratic relationship between the dirty and the clean good depends on a decreasing marginal utility of consumption. Moreover, opposite to AL model it is the decreasing returns to scale in abatement technology (and not increasing returns to scale) which generate the inverse- $U$ curve. If increasing returns are present, then pollution would

\footnotetext{
5 The authors proxy disposal income by household final consumption expenditures.

6 Mazzanti and Zoboli (2008) explain this finding by the presence of economies of scale in recycling activities.
} 
simply be zero (complete decoupling). This result follows from the substitution possibilities in waste disposal. The model in Section 2 does not always result in closed form solutions, thus in Section 3 we present simulation results to report on the behavior of the model, in particular with respect to decoupling possibilities. We find, e.g., that an EKC depends on a quasi-linear utility function and limited diseconomies of scale in recovery activities. If not-recovered waste is taxed, however, there is no inverted-U-shaped curve, but only the downward part of the curve, again subject to the condition that the diseconomies of scale in recovery activities are not too large.

\section{Theoretical model}

\subsection{Linear utility function}

We start with a simple model, based on AL, for comparison. In their model, pollution $P$ is a function of both consumption $C$ and abatement efforts $E, P=C-C^{\alpha} E^{\beta}$, but only abatement is costly. There is so to speak no cost of landfill, but only a disutility of the pollution that remains after abatement. Consider a representative agent which produces waste as a side effect of consumption. We disaggregate waste into two categories: recovered and notrecovered. The representative individual generates or discards as waste a fixed amount $\alpha$ (in kilos per dollar) per unit of the final good consumed (see Appendix A for a motivation on this linear form), which can either be disposed of as not-recovered waste $(w)$ or recovered waste $(r)$. Thus, we assume that not-recovered waste per capita $w$ is given by Eq. (1), where $y$ measures final good consumption per capita:

$w=\alpha y-r, \quad w \geq 0$ and $r \geq 0$

As in AL, we consider a linear utility function with just two arguments, the amount of the final good consumed $y$ and the amount of not-recovered waste $w$ (pollution $)^{7}$ :

$u=y-\gamma w, \quad \gamma>0$

The representative agent faces costs to dispose of waste with or without recovery, depending on the quantities recovered and not-recovered, respectively. Callan and Thomas (2001) estimated landfill and recycling cost functions using data from Massachusetts and found that cost of landfill disposal exhibits constant returns to scale, whereas cost of recycling is characterized by scale economies. In a more recent paper, Bohm et al. (2010) considers municipallevel data for the United States to estimate the costs of municipal waste and curbside recycling services. The authors find that economies of scale prevail for all observed quantities of waste. However, for recycling, economies of scale occur only for low quantities. Therefore, although crucial to establish waste management strategies there is no consensus on the economies of scale present within each waste treatment alternative. ${ }^{8}$ Accordingly, we consider a flexible functional form for the cost function of waste recovered.

\footnotetext{
7 Note that recovery does not enter directly in the utility function. This assumption is in spite the real fact that recycling also creates pollution, and that recovery creates industrial value added. However, this simplifying assumption takes into account that in relative terms recovery is less polluting than non-recovered waste. We thank an anomimous reviewer for pointing this out, and suggesting that the positive effect (value added) from recovered waste on utility and the negative effect (pollution) could be canceling each other out.

8 There is, on the other hand, a significant amount of evidence indicating economies of scale differences within a waste management strategy. EC (1997), e.g. point out that economies of scale can apply to incinerators depending on the type of plant. EC (2013) report that even recycling of paper can differ significantly with respect to the scale economies involved in this activity. The adoption of sensor technologies to separate the plastic from paper, and sort cardboard from paper, can increase significantly the economies of scale in recycling activities.
}

Further, we assume that the cost $C$ of not-recovered waste is proportional to waste $w$ (Eq. (3)). The cost of waste recovery Re, on the other hand, is a non-linear function of recovery effort $r$. Thus, we allow scale (dis)economies in waste recovery, depending on the parameter $\beta$ in Eq. (4). In Eqs. (3) and (4), $\delta$ is a parameter expressed in dollars per kilograms, converting waste as mass into a monetary value:

$C(w)=\delta w$

$\operatorname{Re}(r)=\delta r^{\beta}$

Crucial in our model is the optimal choice between the two disposal alternatives. Even if the unit cost of not-recovered waste would be lower than that of recovered waste, waste generates a disutility (represented by the parameter $\gamma$ ), whereas recovery does not. ${ }^{9}$ The recovered waste cost function gives a straightforward condition for economies of scale, namely that marginal cost are below average cost: $\partial \operatorname{Re} / \partial r<\operatorname{Re} / r$ if $\beta<1$. Total resources $R$ in this representative agent economy are equal to the amount spent on the consumption of the final good, on waste disposal and on recovery activities as in Eq. (5). Eq. (6) gives the Lagrangian to this optimization problem, where Eqs. (1)-(5) are already substituted to express the Lagrangian as a function of $y$ and $r$ only:

$$
\begin{aligned}
& R=y+C(w)+R e(r) \\
& L=y-\gamma \alpha y+\gamma r+\lambda_{1}\left[R-y(1+\alpha \delta)+\delta r-\delta r^{\beta}\right]+\lambda_{2}(\alpha y-r)+\lambda_{3} r
\end{aligned}
$$

The Karush-Kuhn-Tucker necessary first-order conditions (hereafter KKT conditions) associated to this Lagrangian are stated in Eqs. (7)-(15). These conditions result in four cases, labeled by subscripts: case $1\left(w_{1}>0, r_{1}>0\right)$, case $2\left(w_{2}>0, r_{2}=0\right)$, case 3 $\left(w_{3}=0, r_{3}>0\right)$, and case $4\left(w_{4}=r_{4}=0\right)$. Case 4 is trivial and only optimal when resources $R$ are zero. Thus, we focus attention on the other three cases, of which only case 1 is interior $(w>0$ and $r>0)$ and the other two are boundary cases, with either zero recovery (case 2 ) or zero waste (case 3 ):

$$
\begin{aligned}
& \frac{\partial L}{\partial y}=1-\gamma \alpha-\lambda_{1}(1+\alpha \delta)+\lambda_{2} \alpha=0 \\
& \frac{\partial L}{\partial r}=\gamma+\lambda_{1} \delta\left(1-\beta r^{\beta-1}\right)-\lambda_{2}+\lambda_{3}=0 \\
& R=y(1+\alpha \delta)-\delta\left(r-r^{\beta}\right) \\
& \alpha y-r \geq 0 \\
& r \geq 0 \\
& \lambda_{2}(\alpha y-r)=0 \\
& \lambda_{3} r=0 \\
& \lambda_{1}>0 \\
& \lambda_{2}, \lambda_{3} \geq 0
\end{aligned}
$$

\footnotetext{
9 The basic ('coconut') model of $\mathrm{AL}$ (2000: 13) expressed in our notation assumes $\gamma=\alpha=1$ and $C(w)=0$, that is there is no cost to collect waste and to dispose waste as landfill but only a disutility effect. Further, their Cobb-Douglas specification of recovery $r=y^{\mu} \operatorname{Re}^{\nu}$, where the sum $\mu+v$ greater (or smaller) than one determines the occurrence of (dis)economies of scale, can be rewritten as $\operatorname{Re}(r)=\left(r / y^{\mu}\right)^{1 / \nu}$. In our specification, the costs of recovery only depends on the amount of waste to be recovered and the technology parameter $\beta$, whereas AL assume that recovery cost not only varies by the amount of waste to be recovered, but also negatively by the level of consumption.
} 
Case 1 is characterized by strictly positive recovered and non-recovered waste. In this case, $\lambda_{2}$ and $\lambda_{3}$ are equal to zero. Substituting these in Eqs. (7) and (8) results in that the first-order conditions associated to case 1 are such that the marginal rate of substitution $\left(\mathrm{MRS}_{r w}\right)$ and the marginal rate of transformation $\left(\mathrm{MRT}_{r w}\right)$ between recovered waste and not-recovered waste are equal (Eq. (16)), ${ }^{10}$ which results in the reduced form expression for the equilibrium level of $r$ (Eq. (17)) and the indirect utility function $v_{1}$ (Eq. (18)). Moreover, the KKT conditions for case 1 imply that case 1 can never be the optimal outcome when there are constant returns to scale in recovery activities $(\beta=1)$. Additionally, case 1 only holds when the marginal rate of substitution between recovered waste and not-recovered waste is negative, that is, when $1-\gamma \alpha>0$ (see also Appendix B for details and additional restrictions and for the derivation of Eqs. (16) and (17)):

$$
\begin{gathered}
-\frac{1}{(1-\gamma \alpha)}=-\frac{1+\delta \alpha \beta r_{1}^{\beta-1}}{1+\delta \alpha}, \quad \mathrm{MRS}_{w r}=\mathrm{MRT}_{w r} \\
r_{1}^{*}=\left(\frac{\delta+\gamma}{\beta \delta(1-\gamma \alpha)}\right)^{1 / \beta-1} \\
v_{1}^{*}=\left(\frac{1-\gamma \alpha}{1+\alpha \delta}\right) R+\left(\frac{\delta+\gamma}{1+\alpha \delta}\right)\left(\frac{\delta+\gamma}{\beta \delta(1-\gamma \alpha)}\right)^{1 / \beta-1} \\
-\delta\left(\frac{1-\gamma \alpha}{1+\alpha \delta}\right)\left(\frac{\delta+\gamma}{\beta \delta(1-\gamma \alpha)}\right)^{\beta / \beta-1}
\end{gathered}
$$

First of all, the optimal amount of recovered waste in case 1 does not depend on resources or consumption per capita. Second, if recovery faces constant returns to scale, having positive not-recovered waste $(w>0)$ can only be the optimal outcome if individuals do not care about this type of waste (that is the marginal disutility from not-recovered waste is zero). This is intuitive, given that if $\beta=1$, both recovery and not-recovered waste are equally costly. Thus, under constant returns to scale, not-recovered waste would necessarily be zero for $\gamma>0$ (case 3 ). Since increasing returns to scale makes recovered waste more attractive, and not-recovered waste would be zero in the presence of constant returns to scale, it follows that case 1 cannot apply in the presence of increasing returns to scale as well (not-recovered waste would have to be zero).

The intuitive explanation underlined in the above paragraph indicates that case $2(r=0)$ would not hold if $\beta=1$. Moreover, the KKT conditions imply that case 2 is never the optimal solution for any scale (dis)economies in recovery activities (see Appendix B). Here again, the intuition is straightforward: at the margin, when $r$ is close to zero, the marginal cost of recovery is approximately zero while the marginal utility of recovery is always positive $(\gamma)$. Therefore it follows that a solution in which $r=0$ can never be optimal.

Under case 3 , since there is no not-recovered waste, the model simplifies to $r_{3}=\alpha y_{3}$ and $R=y_{3}+\delta r_{3}^{\beta}$. Utility is simply given by consumption (Eq. (19)) and the optimal level of recovery is implicitly defined by Eq. (20). In contrast to the interior case, the amount of waste recovered does not depend on the marginal disutility parameter, but only on total resources $R$ and the share of consumption turned into waste, $\alpha$ :

$u_{3}=y_{3}$

\footnotetext{
10 Similarly, these first-order conditions also imply that the marginal rate of substitution and the marginal rate of transformation between recovered waste and consumption are the same, as well as for not-recovered waste and consumption, $\mathrm{MRS}_{r y}=\mathrm{MRT}_{r y}$ and $\mathrm{MRS}_{w y}=\mathrm{MRT}_{w y}$.
}

Table 1

Cross tabulation of technology parameter $\beta$ and net marginal utility of consumption.

\begin{tabular}{lll}
\hline & $\beta \leq 1$ & $\beta>1$ \\
\hline $1-\gamma \alpha<0$ & Case $3(w=0$ and $r>0)$ & Case $3(w=0$ and $r>0)$ \\
$1-\gamma \alpha>0$ & Case $3(w=0$ and $r>0)$ & Case $1(w>0$ and $r>0)$ \\
& & or $3(w=0$ and $r>0)$ \\
\hline
\end{tabular}

$R=\frac{r_{3}}{\alpha}+\delta r_{3}^{\beta}$

Whether not-recovered waste will be positive (case 1) or not (case 3 ) in the presence of diseconomies of scale in recovery $(\beta>1)$ is unclear, because it depends on the value of the indirect utility function with positive not-recovered waste (Eq. (18)) being higher or lower than the value of the utility function with zero not-recovered waste (Eq. (19)).

The results above can be summarized in two propositions:

Proposition 1. A linear utility function and (constant) economies of scale in recovery of waste, $\beta \leq 1$, results in an equilibrium with zero not-recovered waste.

Proposition 2. A linear utility function and diseconomies of scale in recovery of waste, $\beta>1$, can either result in an equilibrium with zero or positive not-recovered waste, but recovery of waste is necessarily positive.

Corollary to Proposition 2. If $1-\gamma \alpha<0$ then not-recovered waste is zero.

The corollary can be understood as follows. Without recovery, every unit of consumption generates $\alpha$ units of waste, which in turn delivers $\alpha \gamma$ units of disutility. But if the marginal utility of consumption is less than the disutility of waste, $1-\gamma \alpha<0$, then it is better not to consume at all, unless of course waste can be recovered. ${ }^{11}$ Table 1 summarizes the results. Under the assumptions made, case 2 (zero recovery) never applies, the interior case 1 only applies if waste recovery exhibits diseconomies of scale and in all other circumstances the boundary case of zero waste and full recovery applies.

\subsection{No absolute and relative decoupling}

Next, we analyze under what conditions cases $1-3$ presented in Section 2.1, can be related to an EKC, where the pollution variable is not-recovered waste. Absolute decoupling occurs when not-recovered waste decreases while resources increase. Relative decoupling, on the other hand, occurs when the ratio of notrecovered waste and resources decreases when resources increase. In graphical terms (Fig. 1), with an inverse U-shaped EKC, absolute decoupling corresponds to the downward sloping part of the EKC, while relative decoupling starts at the point where a ray from the origin (its angle equal to the ratio $w / R$ ) is tangential to the EKC, which is somewhere on the upward sloping part of the EKC. Thus, absolute decoupling is characterized by $\partial w / \partial R \leq 0$ and relative decoupling by $\partial(w / R) / \partial R<0$. For case 3 not-recovered waste is already zero, thus, both these derivatives would simply be equal to zero. Case 2 is never an optimal equilibrium, and even if it was, it would not be compatible with absolute or relative decoupling. ${ }^{12}$

\footnotetext{
11 When there are economies of scale in recovery $(\beta<1)$, case 1 can apply in the very unlikely case that the optimal amount of recovered waste per capita according to Eq (17) is very small and close to zero. Using Eqs. (3) and (4), the marginal costs of notrecovered waste is higher than of recovered waste only for $r_{1}<\beta^{1 /(1-\beta)}$. Proposition 2 does not take this unlikely case into account.

12 For case 2, the condition for absolute decoupling is the same as the one from case 1 (Eq. (21)), whereas the derivative $\partial(w / R) / \partial R$ is exactly equal to zero, meaning
} 


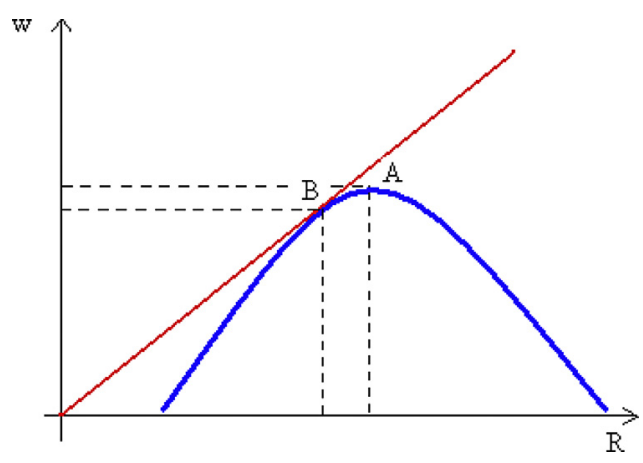

Fig. 1. EKC and decoupling. Notes: For any points in the curve to the right of (A) there is absolute decoupling; for any points in the curve to the right of (B) there is relative decoupling.

Focusing, therefore on case 1 (positive not-recovered waste and recovery), ${ }^{13}$ the conditions for absolute and relative decoupling are given by Eqs. (21) and (22) respectively:

$\frac{\partial w}{\partial R}=\frac{\alpha}{(1+\alpha \delta)}>0$

$\frac{\partial w / R}{\partial R}=\frac{\alpha \delta(\delta+\gamma /(\beta \delta(1-\gamma \alpha)))^{\beta / \beta-1}+(\delta+\gamma /(\beta \delta(1-\gamma \alpha)))^{1 / \beta-1}}{(1+\alpha \delta) R^{2}}$

From Eqs. (21) and (22), we find that case 1 is inconsistent with the presence of absolute and relative decoupling. Relative decoupling is not possible because case 1 can only hold for $1-\gamma \alpha>0$, but then the derivative in Eq. (22) is strictly positive. These findings lead to Proposition 3.

Proposition 3. In an equilibrium with strictly positive recovered and not-recovered waste (case 1 ) and a linear utility function, there is never absolute or relative decoupling.

In terms of the left column of Table 1 , when there is increasing or constant returns to scale, case 3 applies and waste is zero, so a state of complete decoupling is achieved. When there is decreasing returns to scale, either case 3 applies again with complete decoupling, or case 1 applies, with no absolute or relative decoupling but instead waste increases with resources in accordance with Eqs. (21) and (22). Proposition 3 is in contrast with the finding from AL where steadily increasing waste only arises when there are constant returns to scale in abatement, which in our model results in zero landfill waste, that is complete decoupling. ${ }^{14}$ Thus, the absence of absolute or relative decoupling is compatible with a clean environment because in our model it is possible to completely eliminate not-recovered waste, depending on the technology. The simulations in Section 3 indicate that for given parameter values, eliminating not-recovered waste can also occur in the presence of diseconomies of scale in recovery activities.

that any change in resources results in no change in the ratio of not-recovered waste to resources.

13 Using Eqs. (1), (9) and (17) we find $w=1 / 1+\alpha \delta[\alpha R-$ $\alpha \delta((1 / \delta \beta)(\delta+\gamma / 1-\gamma \alpha))^{\beta / \beta-1}-((1 / \delta \beta)(\delta+\gamma / 1-\gamma \alpha))^{1 / \beta-1}$ ] which is used to obtain (21) and (22).

14 Note however, that $\beta$ is given in our model. In reality, this parameter is likely a function of income.

\subsection{Quasi-linear utility function}

We modify the model to allow a quasi-linear utility function of the final good consumed $y$ and not-recovered waste $w$, as given by Eq. $\left(2^{\prime}\right)$.

$u=\ln y-\gamma w, \gamma>0$

The Lagrangian is then given by Eq. ( $\left.6^{\prime}\right)$. Only the KKT condition in Eq. (7) is modified (see Eq. ( $\left.7^{\prime}\right)$ ), whereas the conditions given by Eqs. (8)-(15) remain the same:

$L=\ln y-\gamma \alpha y+\gamma r+\lambda_{1}\left[R-y-\alpha \delta y+\delta r-\delta r^{\beta}\right]+\lambda_{2}(\alpha y-r)+\lambda_{3} r$

$\frac{\partial L}{\partial y}=\frac{1}{y}-\gamma \alpha-\lambda_{1}(1+\alpha \delta)+\lambda_{2} \alpha=0$

The solution to this maximization problem is similar to the one with a linear utility function. Not-recovered waste is zero whenever $\beta$ is equal to one (and therefore also whenever $\beta$ is smaller than one). The model then simplifies to $r=\alpha y$ and $R=y+\delta r^{\beta}$. Utility is simply given by Eqs. $\left(19^{\prime}\right)$ and $\left(20^{\prime}\right)$ implicitly defines the optimal level of recovery. The amount of waste recovered clearly does not depend on the marginal disutility parameter, but only on resources $R$ and the conversion rate $\alpha$ at which consumption turns into waste. That is, if the technology in recovery is efficient enough, not-recovered waste will be zero, regardless of individuals' preferences. A solution where both not-recovered and recovered waste are positive (case 1 ) is subject to the same restrictions as in the linear utility framework, mainly $1-\gamma \alpha>0$ (see also Appendix B). The amount of waste recovered is implicitly defined by Eq. (17') and utility is defined as a function of the amount of waste recovered (Eq. $\left.\left(18^{\prime}\right)\right)$.

$\left(\delta-\beta \delta r_{1}^{\beta-1}\right)\left[\frac{1}{R+\delta r_{1}-\delta r_{1}^{\beta}}-\frac{\gamma \alpha}{1+\alpha \delta}\right]+\gamma=0$

$u_{1}=\ln \left(\frac{R+\delta r_{1}-\delta r_{1}^{\beta}}{1+\alpha \delta}\right)-\gamma\left(\frac{\alpha}{1+\alpha \delta}\left(R+\delta r_{1}-\delta r_{1}^{\beta}\right)-r_{1}\right)$

$u_{3}=\ln y_{3}$

$R=\frac{r_{3}}{\alpha}+\delta r_{3}^{\beta}$

Propositions 1 and 2 and the Corollary to Proposition 2 also hold for the quasi-linear specification of utility.

\subsection{Absolute and relative decoupling}

Taking case 1 (positive not-recovered waste and recovery), the conditions for absolute and relative decoupling when utility is quasi-linear are given by Eqs. $\left(21^{\prime}\right)$ and $\left(22^{\prime}\right)$ respectively, with both expressions depending on the partial derivative $\partial r / \partial R$ given by Eq. (23):

$$
\begin{aligned}
& \frac{\partial w}{\partial R}=\frac{\alpha}{(1+\alpha \delta)}\left[1-\frac{\partial r}{\partial R}\left(\delta \beta r^{\beta-1}-\frac{1}{\alpha}\right)\right] \\
& \frac{\partial(w / R)}{\partial R}=\frac{1}{(1+\alpha \delta)}\left[-\left(\alpha \delta \beta r^{\beta-1}+1\right) \frac{\partial r}{\partial R} R^{-1}+\left(\alpha \delta r^{\beta}+r\right) R^{-2}\right]
\end{aligned}
$$

$\frac{\partial r}{\partial R}=$

$\frac{-\left(\gamma+\gamma \alpha \beta \delta r^{\beta-1}\right)}{\left[-\beta(\beta-1) r^{\beta-2} \delta(1+\alpha \delta-\gamma \alpha R)+\gamma \delta-\gamma \beta \delta r^{\beta-1}(1-\alpha \beta \delta)+\gamma \alpha(2 \beta-1) \beta \delta^{2} r^{2 \beta-2}\right]}$ 
From these equations, we find that, depending on the parameter values, the model can be consistent with the presence of absolute and relative decoupling. These findings lead to Proposition 4, which implies that, an EKC is possible, in this model with a quasi-linear utility function, depending on parameter values. In Section 3.4 we show that when the utility function is quasi-linear an EKC arises for the technology parameter close enough to one (but bounded by $\beta>1$ ).

Proposition 4. Absolute and relative decoupling are a possible (but not necessary) outcome when the utility function is quasilinear.

$R=(1+\alpha \delta+A \alpha \ln R-B \alpha) y-(\delta+A \ln R-B) r+\delta r^{\beta}$

Propositions 1 and 2 also hold for the model with a quasi-linear utility and a tax on not-recovered waste (the proof is similar to the previous models).

As for the model without the tax, absolute and relative decoupling are theoretically possible when case 1 is the optimal solution. When Eq. (21") is smaller or equal to zero there is absolute decoupling and when Eq. $\left(22^{\prime}\right)$ is strictly negative there is relative decoupling. Both expressions depend on $\partial y / \partial R$, given in Eq. (25):

$$
\frac{\partial w}{\partial R}=\frac{1-(\partial y / \partial R)\left(1+\alpha \delta \beta(\alpha y-w)^{\beta-1}\right)-A(w / R)}{\delta-\delta \beta(\alpha y-w)^{\beta-1}+A \ln R-B}
$$

$$
\begin{aligned}
& \frac{\partial(w / R)}{\partial R}=\frac{\left(1-(\partial y / \partial R)-\delta(\alpha(\partial y / \partial R)-(\partial w / \partial R)) \beta(\alpha y-w)^{\beta-1}\right) R-\left(R-y-\delta(\alpha y-w)^{\beta}\right)}{(\delta+\tau) R^{2}} \\
& \frac{\partial y}{\partial R}=\frac{\left.1+(A(r-\alpha y) / R)+\left(A(1-\gamma \alpha y)+\gamma \alpha R(\gamma y+A \ln R-B+\delta) / R(\beta-1)(1-\gamma \alpha y)^{2}\right)[(A \ln R-B+\delta) / \delta \beta) r^{2-\beta}-r\right]}{1+\alpha(A \ln R-B+\delta)-(\gamma /(\beta-1)(1-\gamma \alpha y))\left((A \ln R-B+\delta / \delta \beta) r^{2-\beta}-r\right)}
\end{aligned}
$$

Note that absolute decoupling corresponds only to the downward sloping segment of the EKC, whereas relative decoupling also includes a part of the upward sloping segment of the EKC. Since we found in Section 2.2 that with a linear utility function the EKC is not compatible with the model, we can now conclude that a necessary (but not sufficient) condition for an EKC is that utility is quasi linear.

\subsection{Not-recovered waste tax}

Countries' waste management strategies are closely linked to the implementation of taxes over waste disposal. Within the European Union, countries differ significantly with respect to landfill tax rates. While some European countries (e.g. Denmark, Sweden and the Netherlands) have a tax of landfill disposal around 50 Euros per ton, others adopt a much lower tax (e.g. approximately 5 Euros per ton in Bulgaria) (Bio Intelligence Service, 2012). Such a tax, will evidently, influence the choice between recovery and not-recovered waste, and therefore, the presence (or not) of decoupling. To take this into account, we extend the model from Section 2.3 to incorporate a tax on not-recovered waste $\tau$, as a function of resources (Eq. (24)). ${ }^{15}$ In Eq. (24), the landfill tax rate is a positive function of income. ${ }^{16}$ We assume that this tax decreases net income $\left(5^{\prime \prime}\right)$ and does not increase individuals utility. This could arise if the tax destination (e.g. cleaning up of landfill sites) does not affect individual's directly. Thus, adopting the quasi-linear utility function, the Lagrangian is given by Eq. (6"), and the KKT necessary first order conditions by Eqs. (7") $-\left(9^{\prime \prime}\right)$ and (10)-(15):

$$
\begin{aligned}
\tau= & A \ln R-B ; \tau \geq 0 \\
R= & y+C(w)+\operatorname{Re}(r)+\tau w \\
L= & \ln y-\gamma \alpha y+\gamma r+\lambda_{1}[R+y(\alpha(B-\delta-A \ln R)-1) \\
& \left.\left.\quad+r(\delta-B+A \ln R)-\delta r^{\beta}\right)\right]+\ldots+\lambda_{2}(\alpha y-r)+\lambda_{3} r
\end{aligned}
$$

$$
\begin{aligned}
& \frac{\partial L}{\partial y}=\frac{1}{y}-\gamma \alpha-\lambda_{1}-\lambda_{1} \alpha \delta-\lambda_{1} A \alpha \ln R+\lambda_{1} B \alpha+\lambda_{2} \alpha=0 \\
& \frac{\partial L}{\partial r}=\gamma+\lambda_{1} \delta-\lambda_{1} \delta \beta r^{\beta-1}+\lambda_{1} A \ln R-\lambda_{1} B-\lambda_{2}+\lambda_{3}=0
\end{aligned}
$$

\footnotetext{
15 See Appendix $C$ for a motivation on the log-linear form of the tax rate on resources.

${ }^{16}$ The parameter $B$ has no economical meaning, and it is taken only for estimation purposes. Its value is restricted in such a way that landfill taxes are non-negative.
}

\section{Simulations}

In this section we run simulations using real data from European countries, to further explore the dynamics from our model. In particular, our model showed that in the presence of diseconomies of scale in recovery $(\beta>1)$ whether the equilibrium with zero waste (case 3 ) or positive waste (case 1 ) would arise depended on parameter values. The simulation exercise allows us to explore which of the cases turns out to be the equilibrium. Similarly, with the simulation exercise we can investigate whether absolute or relative decoupling are possible outcomes of our model.

Our sample of countries comprises of 33 European countries (European Union countries - including candidate countries - and Switzerland and Norway). ${ }^{17}$ There is great variation with respect to income level in these countries (ranging from US\$ (constant) 3396 per capita in Macedonia to US\$ (constant) 81,385 per capita in Luxembourg in the year 2010). Alongside GDP per capita, the other real data entering in our simulation exercises is household final consumption expenditure per capita, which also varies significantly in the sample countries (from 2593 in Macedonia to 31,977 in Switzerland). Similarly (but not proportionally), these countries differ in terms of waste management strategies. For illustration purposes we sort these countries into three categories, depending on the share of waste recovered. If this share is below $10 \%$, we categorize them as Group 2 countries (zero recovery) and eight countries belong to this group, mostly Eastern European countries together with Turkey and Malta. If recovery is in between 10 and $90 \%$, then we consider them to belong to the category of interior Group 1. This group contains 22 out of all 33 European countries, among which the large countries Italy, France, Germany, Poland and the UK. Finally, the group of countries categorized as boundary Group 3 with a recovery share higher than $90 \%$ only contains three countries, Denmark, Sweden and Switzerland.

\subsection{Linear utility function}

In the Appendix $C$ we present the parameterization used for the simulations. We estimate the values of $\alpha, \gamma$ and $\delta$, and use the same value of these three parameters for all countries. The values found were $259.65,0.0001$ and 0.0001 respectively. This implies that $1-\gamma \alpha>0$, and case 1 or case 3 may result as the optimal outcome for $\beta>1$. We considered a range of values for the technology parameter $\beta$, from 0.8 to 1.5 . Fig. 2 plots the level of the linear utility for

\footnotetext{
17 We also evaluated the utility function for case 2, but since this case is never optimal, for clarity of exposition, we do not present them in Fig. 2.
} 
Case 2 countries: the amount of waste recovered is below $10 \%$

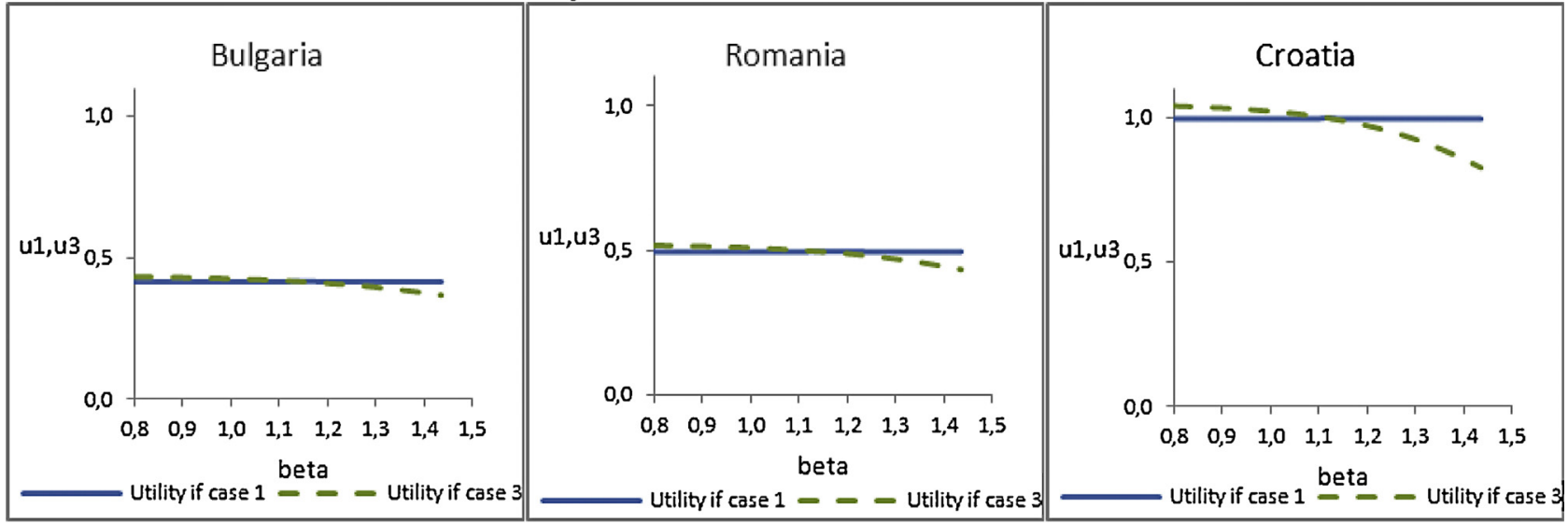

Case 1 countries: the amount of waste recovered is in between 10\% to $90 \%$

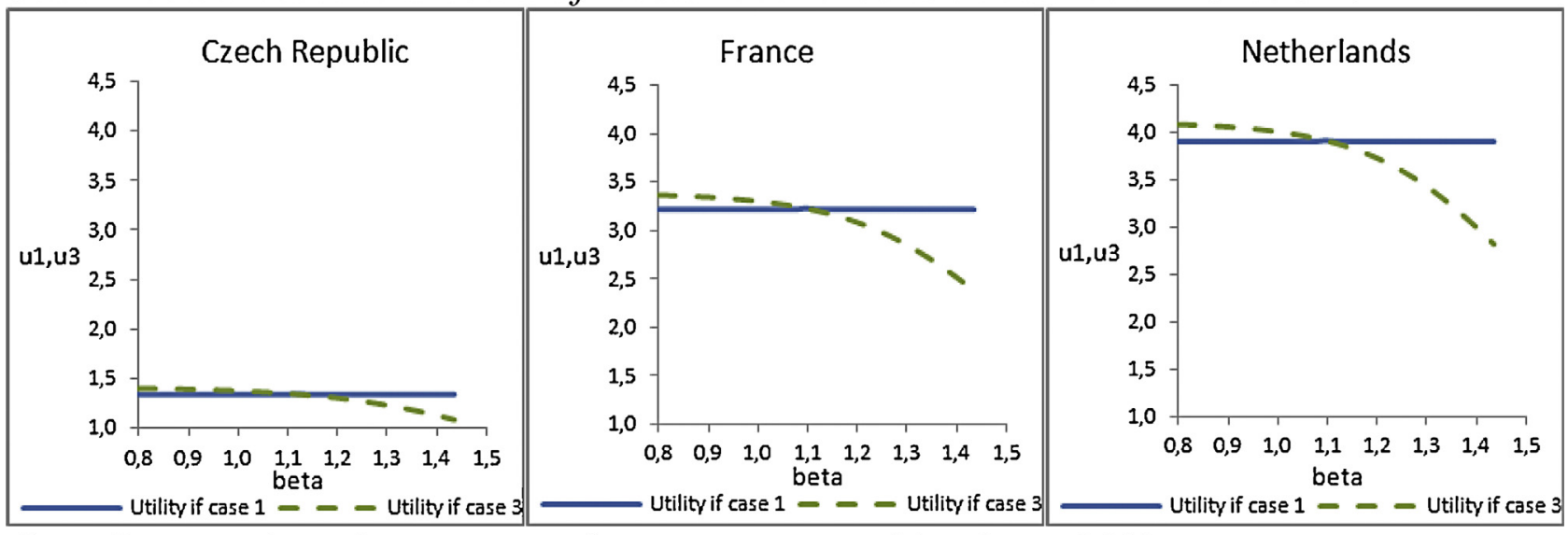

Case 3 countries: the amount of waste recovered is above $90 \%$

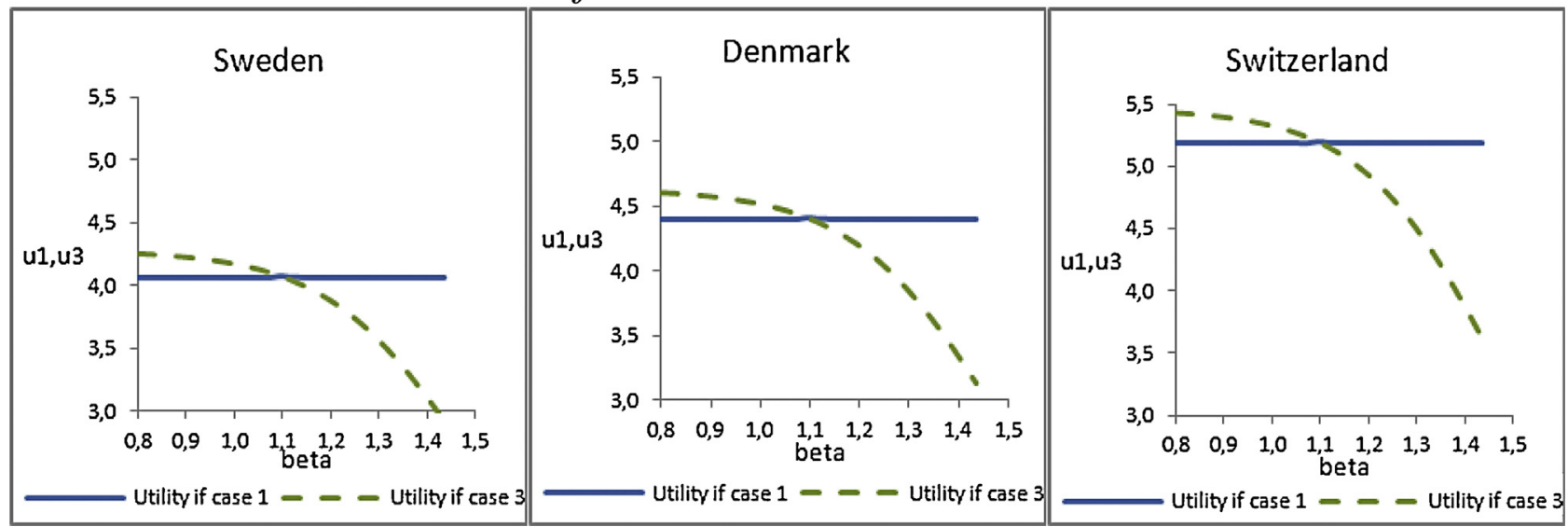

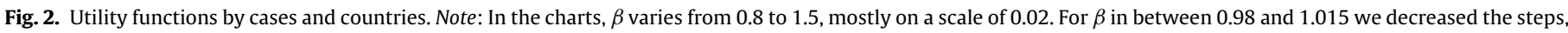
and computed utility values for $\beta$ equal to $0.990 ; 0.995 ; 1.000 ; 1.005 ; 1.015$.

two different scenarios (cases 1 and 3$)^{18}$ as a function of the technology parameter of recovery $\beta$. The figures take as an example, three countries from each group category to determine depending on the value of the technology parameter $\beta$ the levels of utility.

\footnotetext{
18 We have also extended the sample of countries, to include low income and lower middle income countries. The objective was to analyze whether our results would be significantly affected by a much lower income and consumption level. The main results have remained the same, thus we limit the exposition to the European countries data.
}

In line with Table 1 , interior case 1 is optimal only for high values of $\beta$, whereas boundary case 3 (zero waste) is optimal for low values of $\beta$. In particular, for these parameter values it holds that the threshold level of $\beta$, labeled $\beta^{*}$, for which case 3 is optimal is in between $\beta=1.075$ and $\beta=1.115$, depending on resources $R$. For values above $\beta^{*}$, case 1 is optimal, whereas case 2 (not shown in Fig. 2) is never optimal. The empirical findings show that richer countries have lower threshold levels $\beta^{*}$, such that they switch to case 1 at lower levels of $\beta$ than poorer countries. This result is intuitive, given a linear specification of the utility function. The marginal utility of consumption is, in this case, constant. Thus, for given levels of the 
Table 2

Average bilaterial difference in waste not-recovered per capita divided by the difference in GDP per capita in 33 European countries, 2010.

\begin{tabular}{|c|c|c|c|c|c|c|c|}
\hline \multicolumn{4}{|l|}{$\begin{array}{l}\text { Case } 1 \\
\text { countries }\end{array}$} & \multicolumn{2}{|c|}{ Case 2 countries } & \multicolumn{2}{|c|}{ Case 3 countries } \\
\hline Country & $\begin{array}{l}\text { Average } \\
\text { bilateral } \\
\Delta w / \Delta G D P\end{array}$ & Country & $\begin{array}{l}\text { Average } \\
\text { bilateral } \\
\Delta w / \Delta G D P\end{array}$ & Country & $\begin{array}{l}\text { Average } \\
\text { bilateral } \\
\Delta w / \Delta \mathrm{GDP}\end{array}$ & Country & $\begin{array}{l}\text { Average } \\
\text { bilateral } \\
\Delta w / \Delta \text { GDP }\end{array}$ \\
\hline Lithuania & -0.006 & France & -0.009 & Sweden & -0.009 & Macedonia & -0.011 \\
\hline Poland & 0.010 & Germany & -0.002 & Denmark & -0.085 & Serbia & 0.003 \\
\hline Estonia & 0.188 & Belgium & 0.003 & Switzerland & -0.011 & Bulgaria & -0.004 \\
\hline Hungary & 0.003 & United Kingdom & -0.031 & & & Romania & -0.005 \\
\hline Czech Rep. & 0.043 & Finland & -0.033 & & & Latvia & 0.000 \\
\hline Slovak Rep. & 0.043 & Austria & -0.015 & & & Turkey & -0.005 \\
\hline Portugal & -0.006 & Netherlands & -0.009 & & & Croatia & 0.189 \\
\hline Slovenia & -0.006 & Ireland & -0.072 & & & Malta & 0.008 \\
\hline Greece & 0.001 & Iceland & 0.004 & & & & \\
\hline Spain & -0.005 & Norway & -0.004 & & & & \\
\hline Italy & -0.006 & Luxembourg & 0.002 & & & & \\
\hline
\end{tabular}

technology parameter $\beta$, richer countries are less willing to have zero not-recovered waste because their level of consumption and therefore recovery is necessarily higher, thus total recovery costs become too high. Formally, this can be seen by comparing the effect of resources on the utility level if case 1 or case 3 applies (Eqs. (26) and (27) respectively). ${ }^{19}$ Whereas Eq. (26) does not depend on $R$, from (27) it follows that for any given $\beta>1$, the larger the resources (and therefore consumption), the smaller is the impact of resources on utility. Consequently, the richer a country is, the smaller is the benefit of having zero not-recovered waste (case 3 ) for a similar technology parameter $\beta$. This result relies heavily on the assumption that the marginal utility of consumption is constant:

$$
\begin{aligned}
& \frac{\partial v_{1}^{*}}{\partial R}=\frac{1-\gamma \alpha}{1+\alpha \delta} \\
& \frac{\partial u_{3}}{\partial R}=\frac{\partial u_{3}}{\partial y_{3}} \frac{\partial y_{3}}{\partial R}=\frac{\partial y_{3}}{\partial R}=\frac{1}{1+\delta \alpha^{\beta} \beta y_{3}^{\beta-1}}
\end{aligned}
$$

Finally, these quantitative findings indicate that countries such as Denmark, Sweden and Switzerland present scale economies in the recovery of waste. However, this simulation exercise does not provide sufficient information to explain why countries such as Bulgaria and Serbia have zero recovery. In other words, our model qualifies these countries as being in a sub-optimal state. Another explanation for zero recovery countries within the confines of our model is that their marginal disutility of waste $\gamma$ is (perceived to be) equal to zero.

As a robustness check, we experimented with ranges of parameter values for $\gamma(0.00003-0.03), \alpha(10-640)$ and $\delta$ (0.00001-0.000128). For all scenarios, we found a threshold of the technology parameter such that case 1 is optimal for $\beta>\beta^{*}$, and case 3 otherwise. When the threshold level differed with income, then, poorer countries had a higher threshold level $\beta^{*}$ than richer countries. This robustness exercise shows that the threshold level $\beta^{*}$ decreases with the pollution disutility parameter $\gamma$. Thus, if $\gamma$ is high, having zero not-recovered waste becomes more attractive at lower levels of the technology parameter. Additionally, a higher value for $\alpha$ or $\delta$ lowers the threshold level $\beta^{*}$.

\subsection{Linear utility function and decoupling}

The parameter values used in the above simulation give $\partial w / \partial R=253^{20}$ while absolute decoupling requires a negative value for this derivative (see Eq. (21)). Thus, for every additional

\footnotetext{
19 Eq. (26) follows from Eqs. (18) and Eq. (27) from Eqs. (19) and (20).

20 Note that in our simulation we divided resources $R$ by 10,000 (see Appendix C).
}

dollar, not-recovered waste increases by $25.3 \mathrm{~g}$. Using the actual data on waste not-recovered, we can compute the change in waste not-recovered given a change in GDP per capita bilaterally, $\Delta w / \Delta$ GDP. For instance, for Ireland we calculate $\left(w_{\text {Ireland }}-w_{i}\right) /\left(\mathrm{GDP}_{\text {Ireland }}-\mathrm{GDP}_{i}\right)$, where the subscript $i$ refers to all other 32 European countries in the dataset. The overall unweighted average for the year 2010 was $0.05,{ }^{21}$ but there are large cross-country differences (see Table 2), ranging from -0.09 for Ireland to 0.19 for Estonia and Croatia. Fig. 3 plots the actual data on waste not-recovered per capita against GDP per capita for the 33 European countries in 2010. Instead of an EKC, the figure shows that there are two country groups, one for which waste not-recovered per capita is close to zero (qualifying as case 3 countries) and another for which it is high (case 1).

\subsection{Quasi-linear utility function}

Using the same approach as in Section 3.1 (see also Appendix C), we considered as a benchmark the parameter values for $\alpha, \gamma$ and $\delta$ of $259.65,0.0001$ and 0.0001 respectively. The comparison between the value of the utility function if case 1 or case 3 holds was similar to the one resulting from a linear utility function, in the sense that there is a threshold level $\beta^{*}$ such that the interior case 1 with positive waste holds when $\beta>\beta^{*}$ and zero waste case 3 holds otherwise. However, under the quasi-linear utility function $\beta^{*}$ increases with the income level. This is as expected, since when the marginal utility of consumption is decreasing, richer countries tend to care relatively more for the environment and therefore are more likely to switch to case 3 with zero waste than poorer countries. Table 3 reports these findings for the linear and quasi-linear utility functions.

\subsection{Quasi-linear utility function and decoupling}

Using the range of parameter values listed in Table 3, we find evidence of an EKC for technology parameter close enough to one (but bounded by $\beta>1$, otherwise we have complete decoupling). Focusing on the countries for which case 1 was optimal, we observe an EKC for $\beta$ up to 1.315 and relative decoupling for $\beta$ up to 1.355. If the technology parameter is higher than 1.375 , not-recovered waste increases with income level in such a way that there is even no relative decoupling. These results suggest that the occurrence of absolute and relative decoupling can be country-specific, because countries have different recovery technologies. Fig. 4 illustrates

\footnotetext{
21 For every additional dollar, not-recovered waste increases by $50 \mathrm{~g}$.
} 


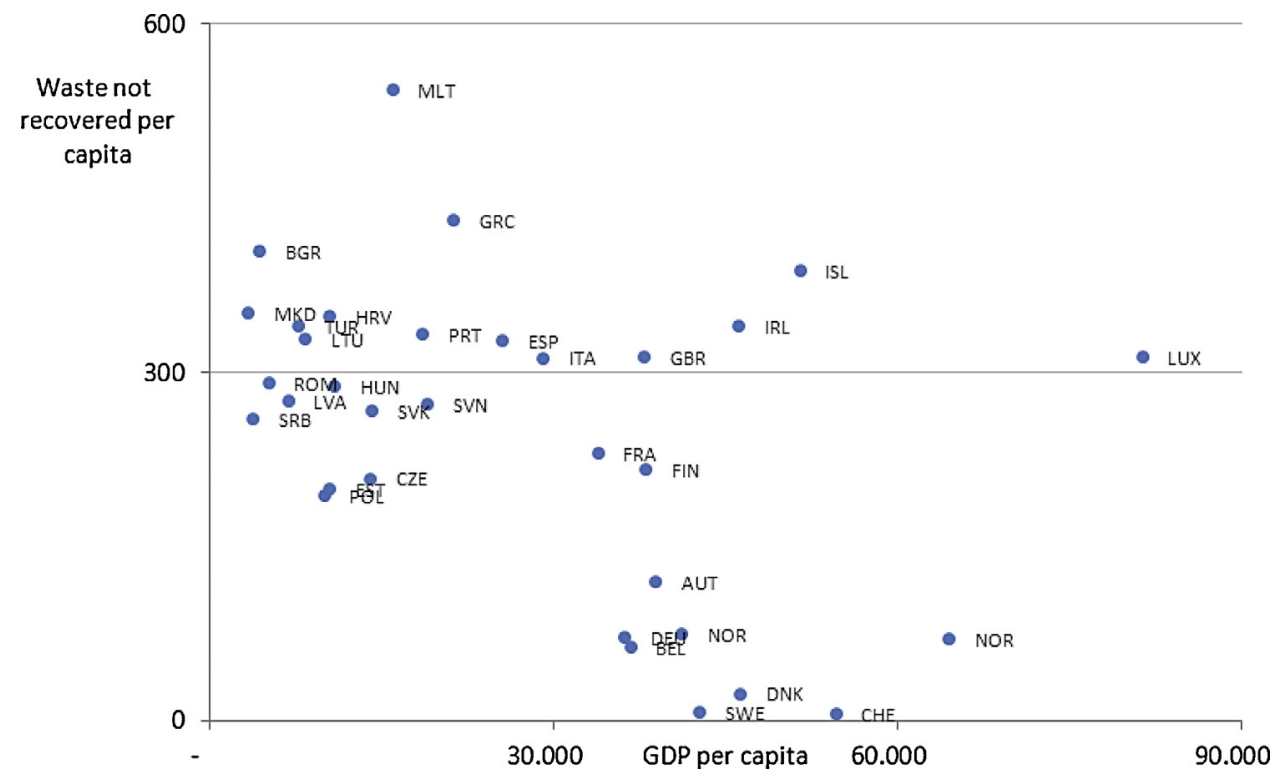

Fig. 3. Waste not-recovered per capita (kg) and GDP per capita in 33 European countries, 2010.
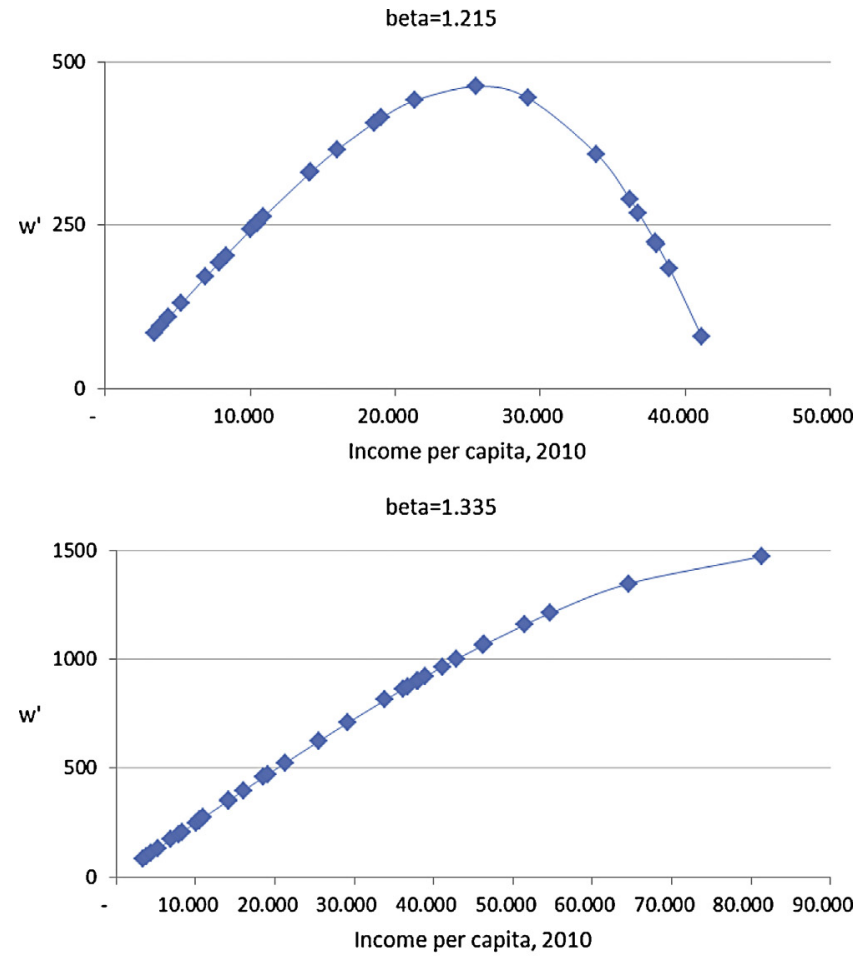

beta $=1.395$

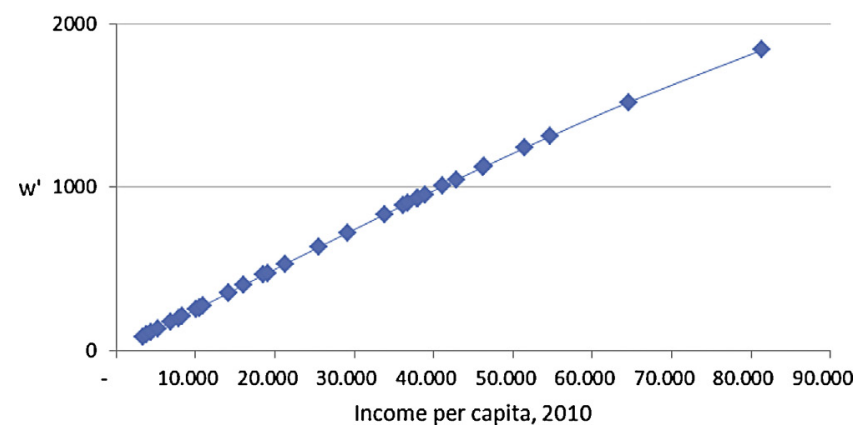

Fig. 4. Quasi-linear utility function and decoupling: predicted values of notrecovered waste against income.
Table 3

Scale economies threshold level for positive (case 1) or zero (case 3) not-recovered waste as a function of income.

\begin{tabular}{llll}
\hline Country & $\begin{array}{l}\beta^{*} \text { linear } \\
\text { utility }\end{array}$ & $\begin{array}{l}\beta^{*} \text { quasi-linear } \\
\text { utility, } \\
\text { No tax }\end{array}$ & $\begin{array}{l}\beta^{*} \text { quasi-linear } \\
\text { utility, } \\
\text { With tax }\end{array}$ \\
\hline Macedonia & 1.115 & 1.055 & 1.100 \\
Serbia & 1.115 & 1.055 & 1.255 \\
Bulgaria & 1.115 & 1.055 & 1.335 \\
Romania & 1.115 & 1.055 & 1.395 \\
Latvia & 1.115 & 1.075 & 1.455 \\
Turkey & 1.115 & 1.095 & 1.475 \\
Lithuania, Poland & 1.095 & 1.095 & 1.495 \\
Estonia, Croatia, Hungary & 1.095 & 1.095 & 1.515 \\
Czech Rep., Slovak Rep. & 1.095 & 1.115 & 1.515 \\
Malta, Portugal, Slovenia & 1.095 & 1.135 & 1.535 \\
Greece & 1.095 & 1.155 & 1.535 \\
Spain, Italy & 1.095 & 1.175 & 1.535 \\
France, Germany, Belgium, UK, & 1.075 & 1.195 & 1.535 \\
$\quad$ Finland, Austria, Netherlands & & & \\
Sweden, Ireland, Denmark, & 1.075 & 1.215 & 1.535 \\
$\quad$ Iceland & & & \\
$\quad$ Switzerland, Norway, & 1.075 & 1.235 & 1.535 \\
$\quad$ Luxembourg & & & \\
\hline
\end{tabular}

Notes: Countries ranked according to their GDP per capita level in the year 2010.

these findings by reporting the predicted value of not-recovered waste for different values of the technology parameter.

\subsection{Quasi-linear utility function and not-recovered waste tax}

Compared to the results from the model without the tax, we find as expected that taxing waste makes not-recovered waste less desirable for any given income level (see Table 3, columns 3 and 4). The threshold level $\beta^{*}$ is pushed upwards across the board, which is natural since taxing waste creates an additional incentive for countries to eliminate not-recovered waste. Thus, only when diseconomies of scale in recovery become very large, measured by $\beta$, is case 1 optimal. Stated otherwise, taking two countries with the same income and recovery technology, we might find the country with a waste taxation belongs to case 3 , while the other belongs to case 1 . This outcome shows that besides technology the institutional setting in a country can determine the optimal outcome. 

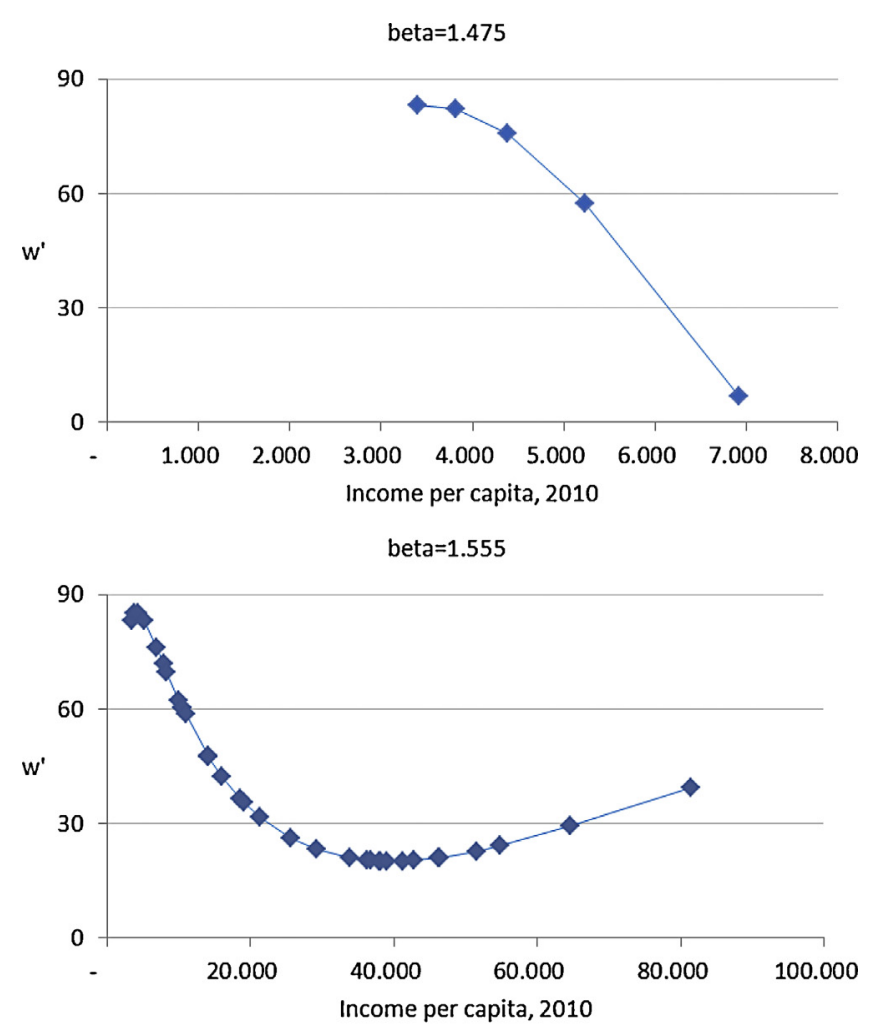

beta $=1.635$

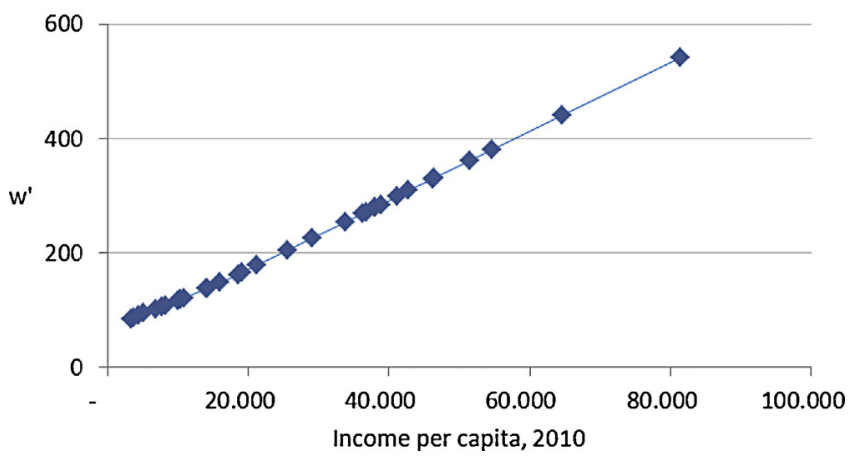

Fig. 5. Quasi-linear utility function with tax and decoupling: predicted values of not-recovered waste against income.

As in the case without the waste tax, when not-recovered waste is taxed, we find evidence of absolute and relative decoupling, but not of an EKC. Fig. 5 depicts not-recovered waste against income for three different values of the technology parameter, for the countries whose optimal outcome is case 1 . There are three possibilities: absolute decoupling (first panel), an U-shape curve (second panel) and a monotonic increase of not-recovered waste as income rises (third panel). Comparing Fig. 5 (with the tax) and Fig. 4 (without the tax) and the third and fourth column of Table 3, shows that the tax implies that case 3 (complete decoupling) becomes optimal at higher levels of the technology parameter. Secondly, although we do not find an indication of an inverted-U-shape relationship, if the technology parameter is not too high, we observe absolute decoupling, whereas a similar value for the technology parameter (e.g. $\beta=1.475$ ) implies a positive relationship between not-recovered waste and income when not-recovered waste is not taxed.

The second panel in Fig. 5 suggests that a technology parameter around 1.555 implies that the amount of not-recovered waste
All countries

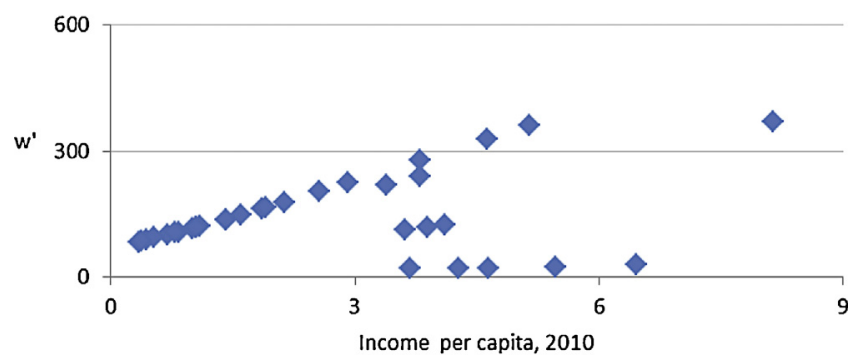

Case 1 countries

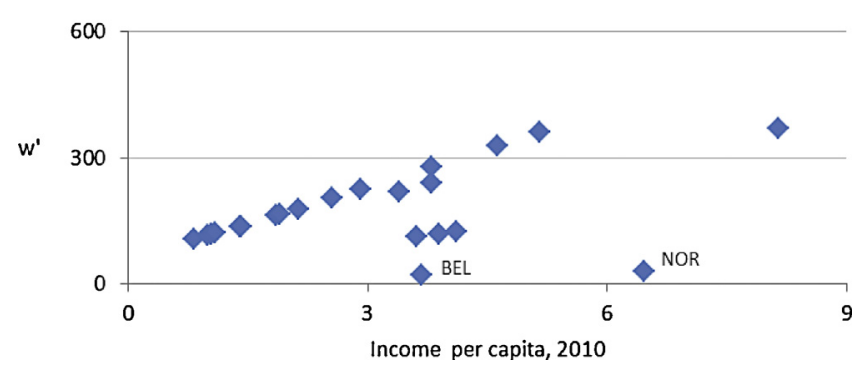

Fig. 6. Quasi-linear utility function with tax and decoupling: predicted values of not-recovered waste against income.

increases as income rises. The explanation is that with strong diseconomies of scale, recovery becomes extremely costly. Therefore, even if a tax on not-recovered waste is charged, higher income countries increase the amount of not-recovered waste to save on recovery costs. This is not the case for lower income countries because they have a tighter budget constraint. Thus, the effect of strong diseconomies of scale is a relative decline of recovery with income and an absolute decline of not-recovered waste. However, noteworthy is that the level of not-recovered waste is still significantly low (compare the y-axis of the second and third panels).

The presence of absolute and relative decoupling depends, therefore, on the technology parameter, which is unknown. Thus, as a final exercise, we use the framework of the quasi-linear utility function with the tax to find, for each country, the technology parameter which minimizes the difference between the predicted and actual value of not-recovered tax (we restrict to $\beta \leq 1.635$ ). Fig. 6 reports these findings by plotting the predicted values of notrecovered waste against GDP per capita. The first panel includes all countries in our sample, whereas the second panel restricts to the countries classified as case 1 countries. Overall, we find that not-recovered waste increases with income (no absolute decoupling). The explanation is the presence of diseconomies of scale (to minimize the difference between actual and predicted values of not-recovered waste, $\beta$ has to be for most countries above 1.615). However, having low levels of not-recovered waste is also possible. Belgium and Norway, for example, have a low predicted value of not-recovered waste because the technology parameter of these countries is estimated at $\beta=1.555$. In other words, a small difference in technology can have a significant impact on the strategy for waste management. Finally, for the technology parameter $\beta$ which minimizes the difference between the predicted and actual levels of not-recovered waste, we found that for some countries $\beta$ had to be significantly higher than the average of the other countries. Thus, a few countries (mainly countries classified as case 3 countries, 
Table 4

Percentage of the waste being recovered or not, depending on technology.

\begin{tabular}{lcc}
\hline & Recovered waste & Not-recovered waste \\
\hline Constant economies of scale & 100 & 0 \\
Increasing economies of scale & 100 & 0 \\
Decreasing economies of scale & $>0$ & $>0$ \\
\hline
\end{tabular}

$r=0)^{22}$ have prohibitively high diseconomies of scale in recovery activities.

\section{Conclusion}

Worldwide countries differ in recovery rates of municipal solid waste generation. Usually, these cross-country differences are related to the development level of each economy. However, even across a relatively homogeneous group of European countries, the differences in recovery rates are striking. In this paper we set up a theoretical framework to find the optimal level of waste recovery which allows for (dis)economies of scale in recovery activities. A crucial feature of our model is that both abatement and conventional disposal of waste such as landfill or incineration without recovery are costly.

Our findings show that (constant) economies of scale in recovery activities result in zero not-recovered waste, whereas notrecovered waste can only result from diseconomies of scale. It is, moreover, suboptimal to have no recovery activities at all, provided there is a marginal disutility of not-recovered waste and marginal costs of recovery are small for low recovery levels. Thus, the waste treatment technology rather than income seem to be the crucial feature for pollution. A country with a low GDP per capita can have zero waste if its waste recovery technology allows scale economies. Analogously, a rich country will still have waste such as landfill if its waste recovery exhibits decreasing returns to scale. Therefore, although the level of income or consumption drives the level of gross pollution, it is not decisive whether what is thrown away will end up as waste or being recovered, or a combination of both (Table 4). Moreover, our model is only compatible with an Environmental Kuznets Curve when there is a diminishing marginal utility of consumption (the quasi-linear utility function). Intuitively, the quasi linear framework makes sense in light of our results. Mainly, we find that with the quasi linear utility function, the Environmental Kuznets Curve arises when countries value the environment (relative to other consumption) more as their income increases. In the linear case, individuals would simply consume more as they become wealthier, such that either countries are in an equilibrium with absolute decoupling (because technologically this is favorable), or waste increases with income. However, our simulation exercises also show that even within the quasi linear framework an inverted-U-shaped pattern is restricted to the cases of limited diseconomies of scale in recovery activities and no taxes.

A final important contribution of our paper is to show that waste management strategies are a combination of development level and recovery technology. Moreover, countries' waste management strategy is influenced by the institutional framework, allowing for complete elimination of pollution even in the presence of diseconomies of scale, illustrated by means of taxation of not-recovered waste. Our quantitative findings also predict that some countries (mainly the poorest countries in our sample) have prohibitively high diseconomies of scale in recovery activities, which might not be realistic. Alternatively, this could be interpreted as high fixed

\footnotetext{
22 Malta, Turkey, Serbia, Romania, Macedonia, Latvia, Croatia and Bulgaria. Additionally, our model also predicts that Greece, Lithuania, Portugal and Hungary (classified as case 1 countries) have a high technology parameter $\beta$.
}

costs of recovery activities. A suggestion for future research is therefore to extend the model by incorporating fixed costs of disposal activities.

\section{Acknowledgements}

We would like to thank Anni Huhtala, Charles van Marrewijk, Gianmarco Ottaviano, Peter Neary, and the participants of the Utrecht School of Economics Seminar Series for usefulcomments and suggestions on a first draft of this paper.

\section{Appendix A. Waste discarded as a constant fraction of income}

In our theoretical model we assume that a constant fraction $\alpha$ of consumption goods (in kilos per dollars) is discarded. Fig. A1 shows, for OECD countries, in each panel approximately a linear pattern between waste treated per capita and consumption per capita (see also Fell et al., 2010).

\section{Appendix B. KIKT conditions}

\section{B.1. Linear and quasi-linear utility functions}

Case 1 associated to the KKT conditions is an equilibrium with strictly positive not-recovered waste $w>0$ and recovery $r>0$. In this case, $\lambda_{1}>0$ and $\lambda_{2}, \lambda_{3}=0$. Together with Eq. (7) (or $\left(7^{\prime}\right.$ ) for the quasi-linear utility function), the condition $\lambda_{1}>0$ implies that the solution associated to positive not-recovered waste and recovery requires $1-\gamma \alpha>0$. Eq. (8) and the conditions $\lambda_{1}>0$ and $\lambda_{2}=\lambda_{3}=0$, on the other hand, result in two restrictions: if $\beta>1$ then $r>(1 / \beta)^{1 / \beta-1}$; and if $\beta<1$ then $r<(1 / \beta)^{1 / \beta-1}$. Case 1 never holds for $\beta=1$.

Case 2 associate to the KKT conditions is an equilibrium with positive not-recovered waste $w>0$ and zero recovery $r=0$. In this case, $\lambda_{2}=\lambda_{3}=0$ and $\lambda_{1}>0$. From Eq. (8) it becomes clear that case 2 never holds, since it implies that $\lambda_{3}=-\left(\gamma+\lambda_{1} \delta\right)$, which is negative for any $\lambda_{1}>0$.

Finally, case 3 is an equilibrium with zero not-recovered waste $w=0$ and strictly positive recovery $r>0$. The KKT conditions imply then that either $\lambda_{2}>\gamma$ and $(\alpha y)^{\beta-1}<1 / \beta$ or $\lambda_{2}<\gamma$ and $(\alpha y)^{\beta-1}>1 / \beta$. None of these constraints impose a restriction on case 3 in such a way that case 3 becomes a non-optimal solution.

To derive that in the interior case 1 the optimum value $r_{1}^{*}=$ $(\delta+\gamma /(\beta \delta(1-\gamma \alpha)))^{1 / \beta-1}$ implies $\mathrm{MRS}_{r w}=\mathrm{MRT}_{r w}$, first consider the consumption side described by $u=y-\gamma w$ and $w=\alpha y-r$. Substituting the latter into the former gives $u(w, r)=[w(1-$ $\gamma \alpha)+r] / \alpha$, so utility is expressed in terms of $w$ and $r$. Solving the total differential $d u(w, r)=(\partial u / \partial w) d w+(\partial u / \partial r) d r=0$ gives the marginal rate of substitution between waste and recovery $\left.(d w / d r)\right|_{d u=0}=-((\partial u / \partial r) /(\partial u / \partial w))=-1 /(1-\gamma \alpha)=$ MRS $_{r w}$. The production side is described by $R=y+C(w)+R e(r)=y+\delta w+\delta r^{\beta}$ and $w=\alpha y-r$, which can be rewritten as $R(w, r)=[w(1+\alpha \delta+$ $\left.r+\alpha \delta r^{\beta}\right] / \alpha$. Solving the total differential $d R(w, r)=(\partial R / \partial w) d w+$ $(\partial R / \partial r) d r=0$ gives the marginal rate of transformation between waste and recovery $\left.(d w / d r)\right|_{d R=0}=-((\partial R / \partial r) /(\partial R / \partial w))=-((1+$ $\left.\left.\alpha \beta \delta r^{\beta-1}\right) /(1+\alpha \delta)\right)=\mathrm{MRT}_{r w}$. Finally, solving MRS $r w=\mathrm{MRT}_{r w}$ for $r$ gives the optimum value described by Eq. (17).

\section{Appendix C. Parameterization}

\section{C.1. Linear utility function}

There is substantial evidence that landfill waste has external costs for individuals (see e.g. Eshet et al., 2006; Rabl et al., 2008; Kinnaman, 2009). The just listed literature provides monetized estimates for these external costs. However, to the best of our 

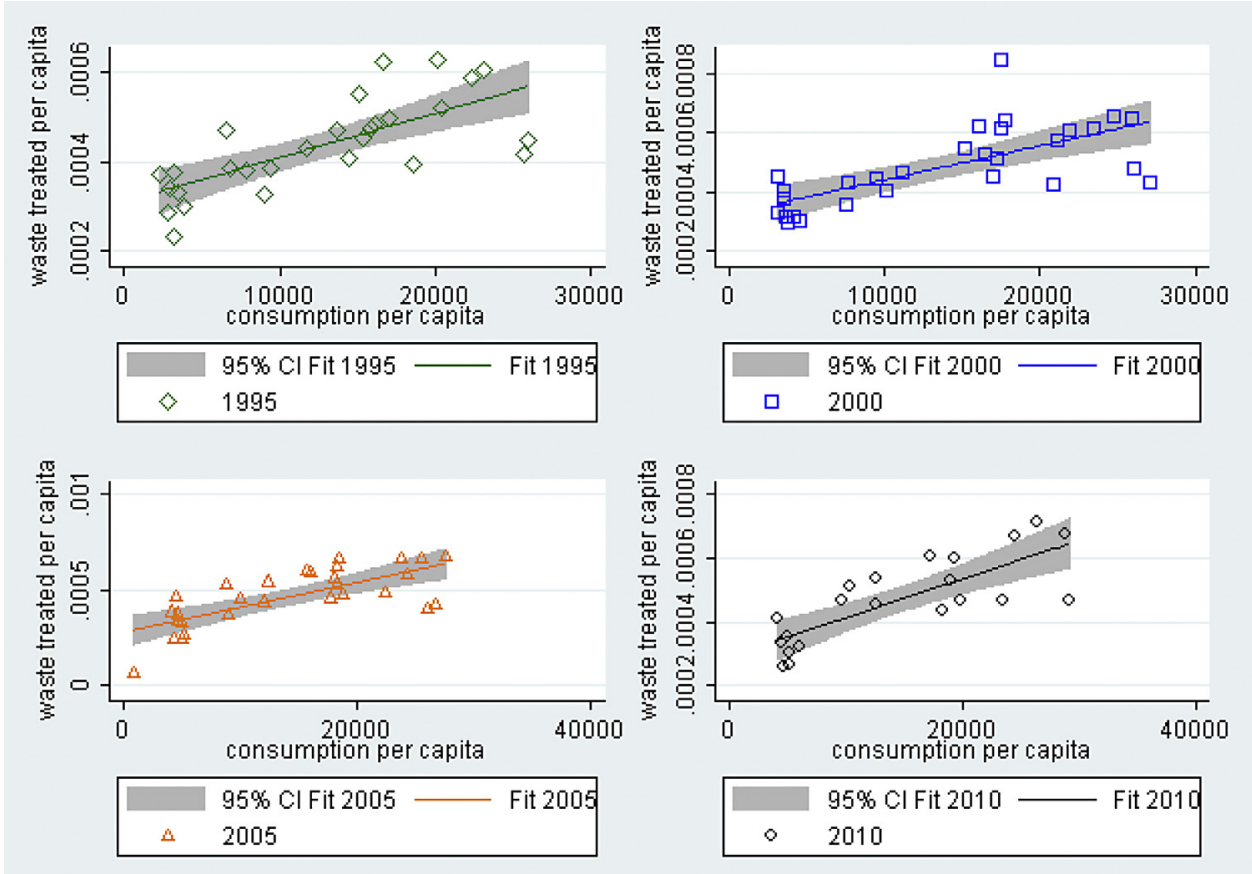

Fig. A1. Waste treated per capita and consumption per capita (constant 2000 US\$) for OECD countries.

knowledge, there is no research yet which estimates the marginal disutility of waste, which depends on an indicator for utility. Based on the monetized estimates for the external costs we can nonetheless infer that the value for the marginal disutility of waste is relatively small. It follows that we consider a range of values for the marginal disutility of waste $\gamma$, in our simulation exercises, ranging from 0.00003 to 0.003 . Our benchmark starting point is the value of 0.0001 .

To estimate the value of $\alpha$, we used 2010 data on (municipal solid) waste recovered per capita $r$, (municipal solid) waste notrecovered per capita $w$, consumption per capita divided by 10,000 $y$. We minimized the sum of squares residuals from Eq. (1). Thus, we performed the following minimization problem:

$\min _{\alpha} \sum_{i=1}^{33}\left(r_{i}+w_{i}-\alpha y_{i}\right)^{2}$

The optimal value of $\alpha$ satisfying the above problem is 259.65 , which translates into about 2.5 kilo of waste per $€ 100$ of consumption.

Using data for the year 2010, we calculated the utility value for each country and different betas values if case 1 (Eq. (9)), case 2 (Eqs. (10) and (11)) and case 3 (Eq. (14)) would prevail.

To estimate the value of $\delta$ we used 2010 Eurostat data for the EU-28 on GDP in billions of euro (12,300), final consumption expenditure of households in billions of euro (7149), the share of general government expenditure of GDP in the EU-27 on "Environment protection" $(0.9 \%)$ and on "Housing and community amenities" (1.0\%) and the amount of waste treated in the EU-27 in kilograms per capita (489), which gives a total of $247,194,518,607 \mathrm{~kg}{ }^{23}$ EUROSTAT (2012a) points out that government spending on "Environment protection" and "Housing and community amenities"

23 http://epp.eurostat.ec.europa.eu/tgm/table.do?tab=table\&init=1\&language=en \&pcode=tec00009\&plugin=1, EUROSTAT $(2012 \mathrm{a}, \mathrm{b})$. Total population in the EU27 in the year 2010 was 505,510,263 (http://appsso.eurostat.ec.europa.eu/ nui/show.do?dataset=demo_pjan\&lang=en). include waste management alongside pollution abatement, protection of biodiversity and landscape, outlays relating to housing development, community development, water supply and street lighting. Thus, waste management alone accounts for less than $1.9 \%$ of GDP. We assume this to be $1 \%$. The above mentioned figures for household consumption and GDP indicate that the share of household consumption from GDP was 58\% (7149/12,300). We allocate the remaining components of GDP $(100-58-1=41 \%)$ proportionally to these two sectors (consumption and waste management). Without differentiating recovered and not-recovered waste, $\delta$ can be estimated from Eq. (5): $R=y+\delta$ Waste, which can be rewritten as $1=0.98+\delta($ Waste $/ R)$, resulting in $\delta=0.02(12,300,014.2 * 1$, $000,000 / 247,194,518,607)(1 / 10,000)=0.0001$. In the final step we divide income $R$ by 10,000 , to be consistent with the metrics adopted before.

\section{C.2. Tax on not-recovered waste}

We use the data from Bio Intelligence Service (2012) on current landfill tax rates (per ton) for the European Union member states to estimate the parameters $A$ and $B$ in Eq. (24). We divide both GDP per capita and the tax rate by 10,000 to keep consistency with the remaining parameters. Fig. A2 reports the observed values of the landfill tax rate together with a logarithm trend line. The coefficients from this trend line gives $A=0.0018$ and $B=0.0009$. However, to restrict the tax to non-negative values, in our simulation we set $A=0.0018$ and $B=0.002$.

\section{Appendix D. Data sources and coverage}

\begin{tabular}{llllll}
\hline Variable & Source & Mean & $\begin{array}{l}\text { Std. } \\
\text { Dev. }\end{array}$ & Min & Max \\
\hline Happiness & $\begin{array}{l}\text { World } \\
\text { Database of } \\
\text { Happiness }\end{array}$ & $6.19^{25}$ & 1.24 & 1.8 & 8.32 \\
& & & & &
\end{tabular}


Current landfill tax (€ per tonne)

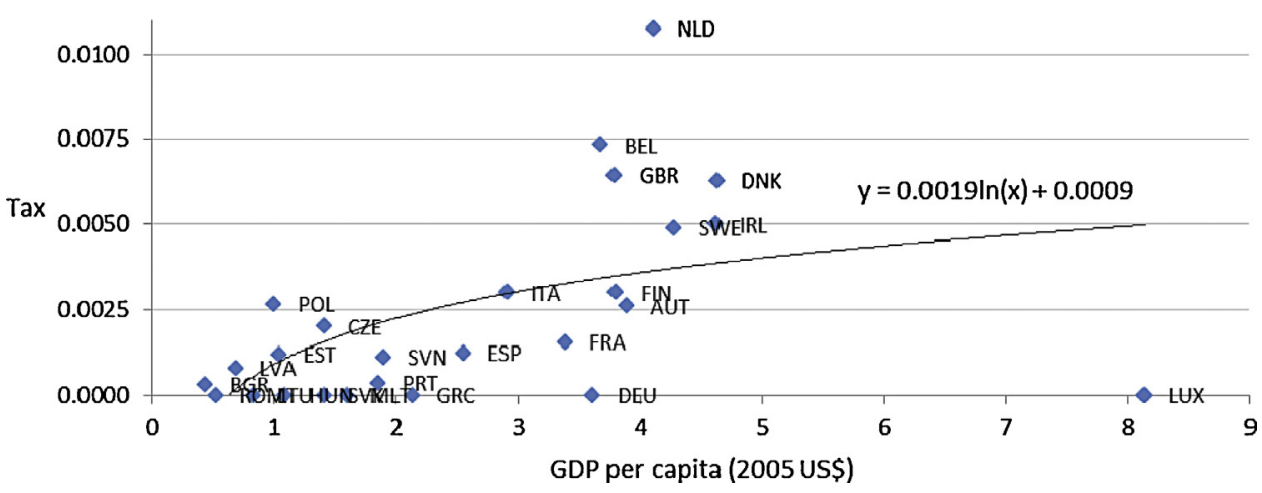

Fig. A2. Landfill tax and income per capita in the European Union. Source: Bio Intelligence Service (2012) and World Bank, WDI (2013). Notes: All data divided by 10,000.

\section{Appendix D (Continued)}

\begin{tabular}{|c|c|c|c|c|c|}
\hline Variable & Source & Mean & $\begin{array}{l}\text { Std. } \\
\text { Dev. }\end{array}$ & Min & Max \\
\hline $\begin{array}{l}\text { Household final } \\
\text { consumption } \\
\text { expenditure per } \\
\text { capita }\end{array}$ & $\begin{array}{l}\text { World Bank, } \\
\text { WDI }\end{array}$ & 1.37 & 0.91 & 0.08 & 3.30 \\
\hline $\begin{array}{l}\text { Waste recovered } \\
\text { per capita }\end{array}$ & Eurostat $^{\mathrm{a}}$ & 197.27 & 189.57 & 0 & 731.22 \\
\hline $\begin{array}{l}\text { Waste } \\
\text { not-recovered } \\
\text { per capita }\end{array}$ & Eurostat $^{\mathrm{a}}$ & 275.84 & 142.01 & 2.57 & 669 \\
\hline $\begin{array}{l}\text { Urbanization } \\
\text { population (\% of } \\
\text { total) }\end{array}$ & $\begin{array}{l}\text { World Bank, } \\
\text { WDI }\end{array}$ & 68.45 & 15.36 & 14.45 & 97.46 \\
\hline $\begin{array}{l}\text { Population } \\
\text { density (people } \\
\text { per sqr km of } \\
\text { land area) }\end{array}$ & $\begin{array}{l}\text { World Bank, } \\
\text { WDI }\end{array}$ & 148.74 & 205.82 & 2.91 & 1299.98 \\
\hline $\begin{array}{l}\text { Life expectancy } \\
\text { at birth, total } \\
\text { (years) }\end{array}$ & $\begin{array}{l}\text { World Bank, } \\
\text { WDI }\end{array}$ & 77.12 & 3.45 & 68.08 & 82.25 \\
\hline $\begin{array}{l}\text { Unemployment, } \\
\text { total (\% of total } \\
\text { labor force) }\end{array}$ & $\begin{array}{l}\text { World Bank, } \\
\text { WDI }\end{array}$ & 9.37 & 6.49 & 2.6 & 37.2 \\
\hline $\begin{array}{l}\text { Inflation, } \\
\text { consumer prices } \\
\text { (annual \%) }\end{array}$ & $\begin{array}{l}\text { World Bank, } \\
\text { WDI }\end{array}$ & 4.08 & 3.56 & -1.09 & 25.23 \\
\hline
\end{tabular}

a To construct the variables 'waste recovered per capita' and 'waste not-recovered per capita' we used two datasets from Eurostat: Treatment of waste ('Data 1'); and Municipal waste generation and treatment, by type of treatment method ('Data 2'). We used Data 1 to obtain the share of incineration with energy recovery. For this purpose we used two data series from Data 1, "Incineration/energy recovery" (Ir) and "Incineration/disposal" (Id). We then constructed the variable share of incineration with energy recovery (SIr) as $\mathrm{SIr}=\mathrm{Ir} /(\mathrm{Ir}+\mathrm{Id})$.

From Data 2, we collected the following variables, "Deposit onto or into land" (D), "Total incineration" (TI), "Material recovery" (R) and "Composting and digestion" (C).

Combining the above information, we constructed the two following variables:

Waste recovered per capita $=\mathrm{R}+\mathrm{C}+\mathrm{TI} \times \mathrm{SIr}$

Waste not-recovered per capita $=\mathrm{D}+\mathrm{TI} \times(1-\mathrm{SIr})$.

Years of data availability are: 2004, 2006, 2008, 2010.

Countries in the dataset are: Albania, Austria, Belgium, Bosnia and Herzegovina, Bulgaria, Croatia, Cyprus, Czech Republic, Denmark, Estonia, Finland, France, Germany, Greece, Hungary, Iceland, Ireland, Italy, Latvia, Liechtenstein, Lithuania, Luxembourg, Macedonia (FYR), Malta, Montenegro, the Netherlands, Norway, Poland, Portugal, Romania, Serbia, Slovak Republic, Slovenia, Spain, Sweden, Switzerland, Turkey, Ukraine, United Kingdom.

\footnotetext{
24 Veenhoven R., Trends in Nations, World Database of Happiness, Erasmus University Rotterdam, http://worlddatabaseofhappiness.eur.nl (2013).

25 The happiness index is based on a survey in which respondents were asked "How satisfied are you with the life you lead?" The answers ranged on a scale from
}

\section{References}

Andreoni J, Levinson A. The simple analytics of the Environmental Kuznets Curve. J Public Econ 2001;80:269-86.

Bio Intelligence Service. Use of economic instruments and waste management performances. Contract ENV.G.4/FRA/2008/0112. European Commission (DG ENV); 2012.

Bohm RA, Folz DH, Kinnaman TC, Podolsky MJ. The costs of municipal waste and recycling programs. Resour Conserv Recycl 2010;54:864-71.

Callan SJ, Thomas JM. Economies of scale and scope: a cost analysis of municipal solid waste services. Land Econ 2001;77(4):548-60.

EC. Economic evaluation of the draft incineration directive, European Commission Report; 1997.

EC. The smart machines that sort through recycled paper, European Commission Research and Innovation article; 2013, http://ec.europa.eu/ research/infocentre/article_en.cfm?artid=20733 [retrieved 11.10.13].

Eshet T, Ayalon O, Shechter M. Valuation of externalities of selected waste management alternatives: a comparative review and analysis. Resour Conserv Recycl 2006;46(4):335-64.

EUROSTAT. General government expenditure: analysis by detailed economic function. Statistics in focus, 33/2012; 2012a.

EUROSTAT. Municipal waste generation and treatment, by type of treatment method. Eurostat Statistic Database. European Commission, Eurostat; 2012b.

Fell D, Cox J, Wilson DC. Future waste growth, modeling and decoupling. Waste Manag Res 2010;28(3):281-6.

Johnstone N, Labonne J. Generation of household solid waste in OECD countries: an empirical analysis using macroeconomic data. Land Economics 2004;80(4):529-38.

Kinnaman TC. The economics of municipal solid waste management. Waste Manag 2009;29:2615-7.

Kinnaman TC, Shinkuma T, Yamamoto M. The socially optimal recycling rate: evidence from Japan. J Environ Econ Manag 2014;68:54-70.

Mazzanti M, Montini A, Zoboli R. Economic dynamics, emission trends and the EKC hypothesis: new evidence using NAMEA and provincial panel data for Italy. Working paper Fondazione Eni Enrico Mattei, Nota di Lavoro 24; 2007.

Mazzanti M, Montini A, Nicolli F. Waste dynamics in economic and policy transitions: decoupling, convergence and spatial effects. J Environ Plan Manag 2012;55(5):563-81

Mazzanti M, Zoboli R. Waste generation, waste disposal and policy effectiveness: evidence on decoupling from the European Union. Resour Conserv Recycl 2008; $52: 1221-34$

Mazzanti M, Zoboli R. Municipal waste Kuznets curves: evidence on socioeconomic drivers and policy effectiveness from the EU. Environ Resour Econ 2009;44:203-30.

Rabl A, Spadaro JV, Zoughaib A. Environmental impacts and costs of solid waste: a comparison of landfill and incineration. Waste Manag Res 2008;26: 147.

Stern DI. The rise and fall of the Environmental Kuznets Curve. World Dev 2004:32(8):1419-39.

World Bank. World Development Indicators. The World Bank; 2013.
1 "not at all" until 4 "very". However, we use the data on a range $0-10$, as proposed by Veenhoven. 